\title{
A Call to Action: Nurse Leader Succession Plan in Acute Care
}

\author{
Mary Kerich \\ Quality/ Performance Improvement Specialist \\ University of Maryland Medical Center, Baltimore, USA \\ E-mail: Marykerich1@gmail.com
}

Received: Sep. 5, $2017 \quad$ Accepted: Sep 17, $2018 \quad$ Published: October 1, 2018

doi:10.5296/jmr.v10i4.11812ＵRL: https://doi.org/10.5296/jmr.v10i4.11812

\begin{abstract}
Nurse leader succession plan in acute care is a business strategy that has a financial impact. Quality care and patient safety is reliant on effective clinical leadership. Efficiency and effectiveness in care delivery processes and outcomes translate into corporate financial sustainability. The premise of nurse leader succession plan is to build leadership capacity for clinicians, and enlarge nursing portfolio. Potential candidates acquire skills and knowledge pertinent to professional growth and leadership roles. Structured mentorship program focus on inter-professional collaboration that enhance clinical and leadership competencies. Individualized professional development plans align competencies with personal career goals. Emerging nurse leaders are inspired to demonstrate commitment and ownership of healthcare processes and outcomes. Regular performance appraisal and feedback provide objectivity in training and development programs. Additionally, communication and relationship management lead to efficiency and mentorship program integration. Succession plan and leadership development advances nursing discipline, autonomy, career development and job satisfaction. Therefore, a nurse leader succession plan provides a reflection on the voice of a nurse in hospital environment.
\end{abstract}

Keywords: Mentorship, Transformational Leadership, Nurse Leader, Succession, Model, Clinical 


\section{Introduction}

The healthcare landscape is evolving rapidly with change in care delivery models, regulatory requirements, demographics, and population health. The nursing discipline is vital to healthcare for providing evidence based high quality care for best outcomes. Transformative leadership and succession plan impact staff morale and productivity. Some health care organizations have a formal succession plan and they develop potential candidates through a structured leadership development programs (Doria, 2015). Acute care sustainability is enhanced through nurse Leader succession plan and leadership development. Strategies for the succession plan include career goal assessment, formal leadership development, formal leadership role, transformational leadership and mentorship (Titzer, Shirey, \& Hauck, (2014).

A nationwide shortage in nursing management exists with fewer nurses going into management. Some nurses opt for different nurse career advancement like nurse educator, nurse practitioner, informatics, research and advocacy (Doria, 2015). Evidently, organizations that identify and develop human resources improve role transition, reduce manager turnover rates and decrease replacement cost.

\section{Contextual Issues}

The contextual issues include organization structure, staff engagement, staff morale, staff turnover, nurse orientation, preceptorship, and mentorship programs. The ontology of leadership succession pivots on the social construct and collegial relationships. Mentorship and leadership succession programs develop positive attitudes and critical thinking capacity for responsibility, insight, intuition and creativity (Andrade, Scherlowski \& da Costa, 2016).A multi-generational workforce merit succession planning as a business strategy in view of nurses shortage. Nurse Leaders must recognize the power of relationships and develop staff to adopt, prosper and grow (Dyess, Sherman, Pratt, \& Chiang-Hanisko, 2016).

A growing multicultural healthcare workforce demands a structured nurse mentorship program to enhance clinical and cultural competencies. Pront, Gillham, and Schuwirth, (2016) contend that clinical supervision and mentorship is complex and requires a comprehensive understanding across the healthcare disciplines. The goal to influence the future of healthcare is supported by empirical studies that demonstrate that minorities are underrepresented in healthcare leadership roles.

Research in healthcare expands on clinical knowledge for evidence based practice. There is an opportunity to explore nursing leadership and succession planning in acute care facilities. Doctors are reluctant to engage in management and leadership positions, other than at the clinical team level (Lees, 2016). Nurse leaders must champion organizational leadership research and become instrumental in the results dissemination. Resources should be allocated to Nurse Leader succession plan that constitutes an essential part in operation excellence.

Nursing epistemology is an art and a science that underpins critical thinking, analytical ability and exemplary leadership that progress intellectual assets (Andrade, Scherlowski \& da Costa, 2016). Succession plan and leadership development advance nursing discipline and autonomy. Organizational cultures that support professional development inspire emerging nurse leaders 


\section{Macrothink}

to demonstrate commitment and ownership in healthcare processes and outcomes.

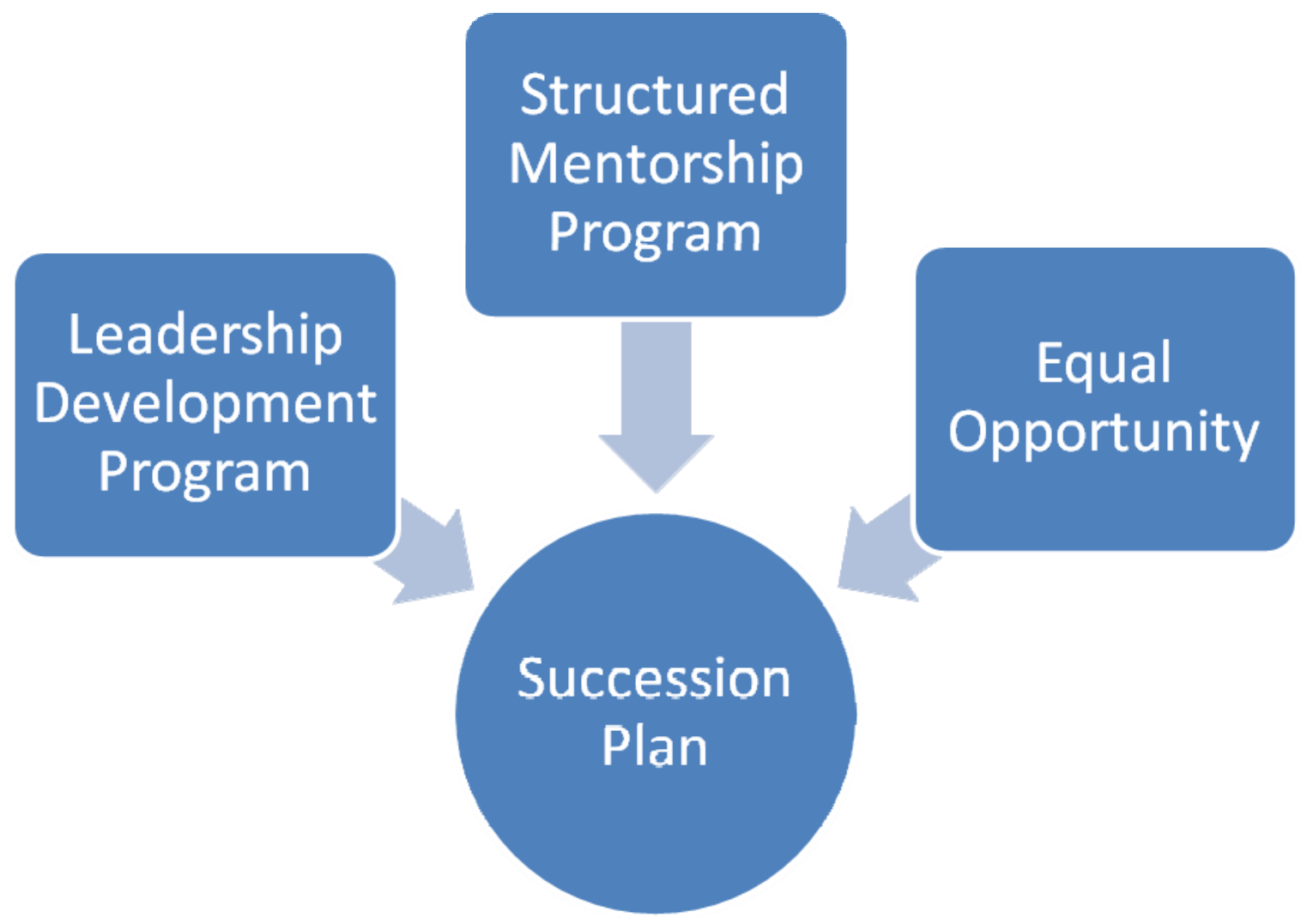

Nurse Leader Succession Model

Transformational leaders inspire their followers and use creativity to impart leadership knowledge and skills for personal and professional growth (Breevaart\& Bakker, 2017). Nurse mentorship includes leadership skill development, professional development, and enabling organizational culture. Mentorship provides intellectual, emotional, and political preview for exemplary leadership (Elidas, Jabubik, Weese \& Huth, 2017).Acute care hospitals are entrusted to provide safe, timely, and effective patient care in an efficient manner. System thinking and partnerships engage all the stakeholders to share their insights, perceptions of care process and opportunities' that progress quality and patient safety.

The institute of Medicine describe patient-centered care as one of the six elements of high quality health care that build on discussions and decisions that involve shared information, relationship building and empowering care provision (Hashim, 2017).Patient safety and optimal outcomes are paramount. Nursing caring theory provide a framework to advance patient- centered care through effective communication, teamwork, mutual support and trust. Scientific knowledge and technical skills are imperative to quality nursing care(Palos, 2014).

Comprehensive unit based safety program enlists healthcare team approach. A structured mentorship program equips registered nurses with added skills through innovation and partnerships (Conway \& Coyle, 2017).Transformative leadership encompasses motivation; interpersonal communication; conflict resolution, and negotiation. Nurse leader succession 
plan is critical to care delivery in acute care hospitals.

\section{Conclusion}

Transformative leadership empowers the staff to advocate for quality and patient safety. High rate of employee turnover impede continuity of quality care. Hospital leadership structure must provide an enabling environment, and focus staff development. An inclusive organizational culture that affords equitable career advancement opportunities is evidence of positive social change. The Advocacy for low-cost innovative approach to succession planning is timely. Active engagement with individuals across the healthcare continuum is pertinent to innovative training strategies. Effective leadership reduces medical errors and increase compliance with Government and regulatory agencies rules for best outcomes. McFadden, Stock, \& Gowen III (2015) demonstrate the essence of transformational leadership in correlation to continuous quality improvement initiatives, and improved patient safety. Nurse leader succession planning demonstrates professional excellence a trajectory that secure future nurse leaders.

\section{References}

Andrade Dias, J. A., Scherlowski Leal David, H. M., \& da Costa Vargens, O. M. (2016). Science, nursing and critical thinking-epistemological reflections. Journal Of Nursing UFPE / Revista De Enfermagem UFPE, 103669-3675.

Breevaart, K., \& Bakker, A. B. (2017). Daily Job Demands and Employee Work Engagement: The Role of Daily Transformational Leadership Behavior. Journal Of Occupational Health Psychology. https://doi.org/10.1037/ocp0000082

Conway, P. H., \& Coyle, S. (2017). Partnership for Patients: Innovation and Leadership for Safer Healthcare. Journal Of Healthcare Management, 62(3), 166-170. https://doi.org/10.1097/JHM-D-17-00039

Doria, H. (2015), Successful transitioning from staff nurse to nurse manager. Nurse Leader Elsevier Inc,1541-4612/2014

Dyess, S. M., Sherman, R. O., Pratt, B. A., \& Chiang-Hanisko, L. (2016). Growing Nurse Leaders: Their Perspectives on Nursing Leadership and Today's Practice Environment. Online Journal Of Issues In Nursing, 21(1), 3.

Eliades, A., Jakubik, L., Weese, M., Huth, J., (2017).v Mentoring Practice and Mentoring Benefit 6: Equipping for Leadership and Leadership Readiness -- An Overview and Application To Practice Using Mentoring Activities. Pediatric Nursing, 43(1), 40-42

Hashim, M. J. (2017). Patient-Centered Communication: Basic Skills. American Family Physician, 95(1), 29-34.

Lees, P. (2016). Clinical leadership -- are clinicians up for it? Clinical Medicine, 16(1), 5-6. Human Resources as a Strategic Partner. (2015). Trustee, 68(9), 4.

McFadden, K. L., Stock, G. N., \&Gowen III, C. R. (2015). Leadership, safety climate, and 


\section{Macrothink}

Journal of Management Research

ISSN 1941-899X 2018, Vol. 10, No. 4

continuous quality improvement: Impact on process quality and patient safety. Health Care Management Review, 40(1), 24-34 11p. https://doi.org/10.1097/HMR.0000000000000006

Palos, G. R. (2014). Care, Compassion, and Communication in Professional Nursing: Art, Science, or Both. Clinical Journal Of Oncology Nursing, 18(2), 247-248. https://doi.org/10.1188/14.CJON.247-248

Pront, L., Gillham, D., \& Schuwirth, L. T. (2016). Competencies to enable learning-focused clinical supervision: a thematic analysis of the literature. Medical Education, 50(4), 485-495. https://doi.org/10.1111/medu.12854

Titzer, J. L., Shirey, M. R., \& Hauck, S. (2014). A nurse manager succession planning model with associated empirical outcomes. The Journal Of Nursing Administration, 44(1), 37-46. https://doi.org/10.1097/NNA.0000000000000019 